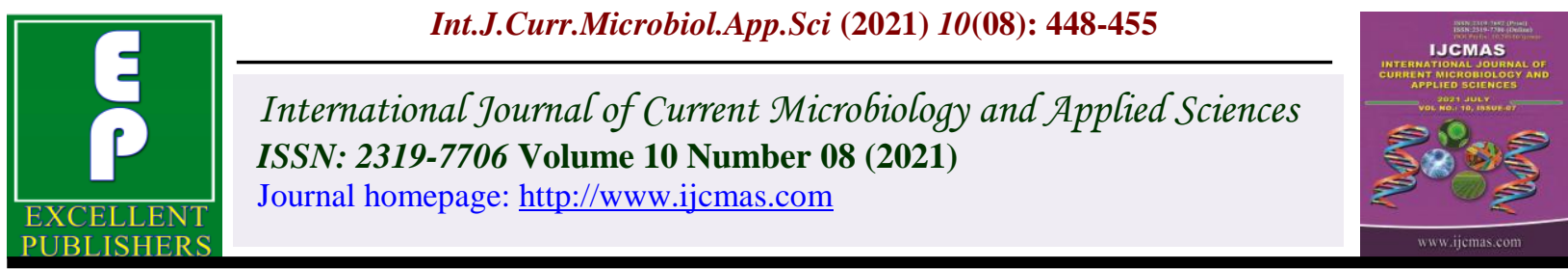

\title{
Microbiological Profile of Chronic Suppurative Otits Media and their Antibiogram in A Rural Tertiary Care Hospital
}

\author{
D. C. Shwetha ${ }^{1}$, G. C. Ravi ${ }^{2}$, D. Venkatesha ${ }^{1}$, S. Megha ${ }^{1}$ and P. G. Greeshma ${ }^{2}$ \\ ${ }^{1}$ Department of Microbiology, ${ }^{2}$ Department of ENT, AIMS, B G Nagara, \\ Mandya-571448, India \\ *Corresponding author
}

\section{A B S T R A C T}

\section{Keywords}

Chronic suppurative otitis media, Sabouraud Dextrose agar, antibiotic susceptibility testing, Pseudomonas aeruginosa

\section{Article Info}

\section{Accepted:}

20 July 2021

Available Online: 10 August 2021
Chronic suppurative otitis media (CSOM) is one of the major causes of deafness in India. The chronicity of the disease and poor response to routine antimicrobials prompted us to isolate and identify the causative organisms and study antimicrobial susceptibility pattern. The ear discharge was collected using two sterile cotton swabs. One swab was used for performing Gram's stain and $\mathrm{KOH}$ mount. The second swab was used to inoculate Blood agar, MacConkey agar and Sabouraud Dextrose agar (SDA) for the isolation of aerobic bacteria and fungal pathogens. The antibiotic susceptibility testing of the bacterial isolates was done by Kirby Bauer's Disc Diffusion method according to CLSI Guidelines. Among 104 samples included in the study, Single bacterial growth was obtained in 69 (66.3\%) samples and single fungal growth was seen in $24(23.1 \%)$ samples. Mixed growth was seen in $6(5.8 \%)$ samples and no growth was observed in $5(4.8 \%)$ samples. Among the bacteria Pseudomonas aeruginosa (30.5\%) was the predominant isolate and Aspergillus niger (8.6\%) was the predominant isolate among fungi. Majority of the Gram negative isolates were sensitive to imipenem and all the Staphylococci isolates were sensitive to vancomycin, teicoplanin and linezolid. Periodic monitoring of microbiological profile is essential for the effective management of CSOM cases in a particular geographical area.

\section{Introduction}

Chronic suppurative otitis media (CSOM) is a chronic inflammation of the middle ear cleft, with permanent abnormality of tympanic membrane which presents as recurrent otorrhea. Patients presenting with tympanic membrane perforations and discharging ear for a period of 3 months or more, despite medical treatment are recognized as CSOM cases (Mehta, et al., 2017).Incidence of this disease is higher in developing countries especially in low socio-economic group because of malnutrition, overcrowding, poor hygiene and inadequate health care (Rajesh, et al., 2017). 
It is a disease of multiple etiologies and is well known for its persistence and recurrence in spite of treatment. CSOM is the leading cause of preventable hearing loss in the developing world (Toleti, et al., 2016).

Untreated cases of CSOM can result in various complications such as persistant otorrhea, mastoiditis, labyrinthitis and facial nerve paralysis to serious complications like meningitis, intracranial abscess and thrombosis.

So, timely management of CSOM cases is important (Harshika, et al., 2015). Most common organisms found in CSOM are Pseudomonas, Staphylococcus aureus, Proteus mirabilis, Klebsiella, E.coli, Aspergillus species and Candida. These organisms vary among geographical area (Shreshta, et al., 2011).

Microbial predominance and their antibiotic sensitivity pattern change over time. The knowledge of local pattern of infections is essential to enable efficacious treatment of this disease and thereby reducing risks of complications (Arvind, et al., 2014).

So, the present study was undertaken to know the microbiological profile of CSOM and their antibiotic sensitivity pattern in our set up. This knowledge is very important for the clinicians in the appropriate management of cases and to prevent complications associated with it.

\section{Materials and Methods}

This prospective study was conducted for a period of 2 years from September 2018 to September 2020 in the department of Microbiology and in association with the department of ENT of a tertiary care hospital. The study includes 104 clinically diagnosed cases of CSOM attending the Outpatient department of ENT.

\section{Inclusion criteria}

Patients with persistent or intermittent ear discharge in one or both ears for more than 3 months duration, irrespective of age and gender

\section{Exclusion criteria}

Patients with ear discharge with intact tympanic membrane (Otitis externa) and Patients on antibiotics or antifungal drugs (Topical or systemic) at the time of presentation or within a week of presentation

\section{Sample collection}

The ear discharge was collected using two sterile cotton swabs under aseptic precautions with the help of an aural speculum. Samples were collected from each ear separately in case of bilateral infection and transported immediately to the Microbiology laboratory for further processing.

\section{Sample processing}

One swab was used for performing Gram's stain and $\mathrm{KOH}$ mount. A thin smear was prepared using a clean glass slide, Gram staining is done and examined under oil immersion objective of the microscope for the presence of pus cells, bacteria and budding yeast cells. $\mathrm{KOH}$ mount is prepared and examined under high power objective for presence of fungal elements. The second swab was inoculated onto Blood agar, MacConkey agar for the isolation of aerobic bacteria and onto Sabouraud Dextrose agar (SDA) for the isolation of fungal pathogens.

\section{Aerobic culture}

The inoculated aerobic bacterial cultures was incubated at $37^{\circ} \mathrm{C}$ for $18-24$ hours. The bacterial growth was identified based on 
morphology, cultural characteristics and biochemical reactions according to standard microbiological methods (Collee JG et al., 1996). The antibiotic susceptibility testing of the bacterial isolates was performed as per Kirby Bauer's Disc Diffusion method on Mueller Hinton agar using the preferable antibiotics and interpretation is done based on CLSI Guidelines.

\section{Fungal culture}

The specimen inoculated onto SDA was incubated at room temperature. The growth was identified based on morphology and cultural characteristics. Tease mount was examined microscopically using Lactophenol Cotton Blue (LPCB) staining technique. Antifungal susceptibility testing is not done in the present study.

\section{Results and Discussion}

A total of 104 patients were included in the study. Ear swabs from all the patients were collected and sent to the microbiology laboratory for culture. Single bacterial growth was obtained in $69(66.3 \%)$ samples and single fungal growth was seen in $24(23.1 \%)$ samples. Mixed growth was seen in $6(5.8 \%)$ samples and no growth of bacteria or fungi was observed in 5 (4.8\%) samples (Table.1).

A total of 105 (76 bacterial \& 29 fungal) isolates were obtained from 104 samples. Distribution of bacteria and fungi causing CSOM is shown in Table.2. Among the bacterial isolates, Pseudomonas aeruginosa $(30.5 \%)$ was the predominant isolate obtained followed by Staphylococcus aureus (11.4\%), Klebsiella (7.6\%), MRCONS (4.8\%), Citrobacter (4.8\%), NFGNB (3.8\%), MRSA (3.8\%), CONS (2.9\%), Proteus $(1.9 \%)$ and Escherichia coli (0.9\%). Among the fungal isolates, Aspergillus niger $(8.6 \%)$ was the predominant organism followed by
Aspergillus fumigatus (6.6\%), Candida albicans (5.7\%), NAC (3.8\%) and Aspergillus flavus $(2.9 \%)$.

Out of the 104 cases, 6 showed mixed isolates. $P$. aeruginosa was seen in combination with A. fumigatus, $C$. albicans, Coagulase negative Staphylococcus and Klebsiella. S. aureus was seen with $A$. niger growth and Non albicans Candida with A. fumigatus which is depicted in Table.3.

Antibiotic sensitivity testing was done for all the bacterial isolates. All culture media and antibiotic discs were procured from Himedia Laboratories Private Limited. In the present study, majority of the $P$. aeruginosa isolates were sensitive to Imipenem $(90.6 \%)$ followed by ciprofloxacin $(87.5 \%)$, netilmicin $(87.5 \%)$, tobramycin $(84.4 \%)$, meropenem $(84.4 \%)$, amikacin (81.2\%), ofloxacin (81.2\%), gentamicin $(78.1 \%)$, piperacillin tazobactum $(59.4 \%)$, cefipime $(56.2 \%)$, ceftazidime $(50 \%)$ and amoxiclav (37.5\%) (Table.4).

Gram positive isolates like $S$. aureus, MRSA, CONS, MRCONS showed $100 \%$ sensitivity to vancomycin, linezolid and teicoplanin. They showed increased sensitivity to gentamicin (91.7\%), tetracycline (87.5\%), amikacin $(87.5 \%)$, followed by cotrimoxazole $(79.2 \%)$, azithromycin (79.2\%), amoxiclav (58.3\%), clindamycin $(45.8 \%)$, erythromycin $(45.8 \%)$ and less sensitive to penicillin (33.3\%) shown in Table.5. Sensitivity pattern of other Gram negative bacilli is shown in table.6. Chronic suppurative otitis media (CSOM) is one of the most common childhood diseases worldwide.

Its prevalence is related to poor socioeconomic conditions and common in developing countries. Research into the microbial causes of CSOM has so far been reliant on culture-based techniques (Neeff, et al., 2016). Poorly treated or untreated CSOM can lead to many complications. 
Table.1 Growth seen in CSOM cases

\begin{tabular}{|c|c|c|}
\hline Growth & Number & Percentage \\
\hline Single bacterial culture & 69 & 66.3 \\
\hline Single fungal culture & 24 & 23.1 \\
\hline Mixed growth & 6 & 5.8 \\
\hline No growth & 5 & 4.8 \\
\hline Total & 104 & 100 \\
\hline
\end{tabular}

Table.2 Distribution of organisms causing CSOM

\begin{tabular}{|c|c|c|}
\hline Organisms isolated & Number & Percentage \\
\hline BACTERIA & 32 & 30.5 \\
\hline $\begin{array}{c}\text { Pseudomonas aeruginosa } \\
\text { Staphylococcus aureus }\end{array}$ & 12 & 11.4 \\
\hline Klebsiella & 8 & 7.6 \\
\hline $\begin{array}{c}\text { Methicillin Resistant Coagulase negative Staphylococcus } \\
\text { aureus (MRCONS) }\end{array}$ & 5 & 4.8 \\
\hline Citrobacter species & 5 & 4.8 \\
\hline Methicillin Resistant Staphylococcus aureus (MRSA) & 4 & 3.8 \\
\hline Non fermenting Gram negative Bacilli (NFGNB) & 4 & 3.8 \\
\hline Coagulase Negative Staphylococcus aureus (CONS) & 3 & 2.9 \\
\hline Proteus species & 2 & 1.9 \\
\hline Escherichia coli & 1 & 0.9 \\
\hline FUNGI & & \\
\hline Aspergillus niger & 9 & 8.6 \\
\hline Aspergillus fumigatus & 7 & 6.6 \\
\hline Candida albicans & 6 & 5.7 \\
\hline Non albicans Candida (NAC) & 4 & 3.8 \\
\hline Aspergillus flavus & 3 & 2.9 \\
\hline Total & 105 & $\mathbf{1 0 0}$ \\
\hline
\end{tabular}

Table.3 Distribution of mixed isolates in CSOM

\begin{tabular}{|c|c|}
\hline Mixed isolates & Number \\
\hline P. aeruginosa + A. fumigatus & 1 \\
\hline P. aeruginosa + C. albicans & 1 \\
\hline S. aureus + A. niger & 1 \\
\hline P. aeruginosa + CONS & 1 \\
\hline P. aeruginosa + Klebsiella & 1 \\
\hline NAC + A. fumigatus & 1 \\
\hline Total & $\mathbf{6}$ \\
\hline
\end{tabular}


Table.4 Antibiotic sensitivity pattern of Pseudomonas aeruginosa

\begin{tabular}{|c|c|c|c|c|}
\hline \multicolumn{2}{|c|}{ Sensitive } & \multicolumn{2}{c|}{$(\mathrm{n}=32)$} \\
\hline Antibiotic & \multicolumn{2}{|c|}{ Resistant } \\
\hline Imepenem & Number & percentage & Number & Percentage \\
\hline Ciprofloxacin & 29 & 90.6 & 3 & 9.4 \\
\hline Netilmicin & 28 & 87.5 & 4 & 12.5 \\
\hline Tobramycin & 28 & 87.5 & 4 & 12.5 \\
\hline Meropenem & 27 & 84.4 & 5 & 15.6 \\
\hline Amikacin & 26 & 84.4 & 5 & 15.6 \\
\hline Ofloxacin & 26 & 81.2 & 6 & 18.8 \\
\hline Gentamicin & 25 & 81.2 & 6 & 18.8 \\
\hline Piperacillin & 19 & 78.1 & 7 & 21.9 \\
tazobactum & & 59.4 & 13 & 40.6 \\
\hline Cefipime & 18 & & & 43.8 \\
\hline Ceftazidime & 16 & 56.2 & 14 & 50 \\
\hline Amoxyclav & 12 & 50 & 16 & 62.5 \\
\hline
\end{tabular}

Table.5 Antibiotic sensitivity pattern of Staphylococcus species

\begin{tabular}{|c|c|c|c|c|}
\hline Antibiotic & \multicolumn{2}{|c|}{ Sensitive } & \multicolumn{2}{c|}{ Resistant } \\
\hline & Number & percentage & Number & Percentage \\
\hline Vancomycin & 24 & 100 & 00 & 00 \\
\hline Linozolid & 24 & 100 & 00 & 00 \\
\hline Teicoplanin & 24 & 100 & 00 & 00 \\
\hline Gentamicin & 22 & 91.7 & 2 & 8.3 \\
\hline Amikacin & 21 & 87.5 & 3 & 12.5 \\
\hline Tetracycline & 21 & 87.5 & 3 & 12.5 \\
\hline Azithromycin & 19 & 79.2 & 5 & 20.8 \\
\hline Cotrimoxazole & 19 & 79.2 & 5 & 20.8 \\
\hline Amoxyclav & 14 & 58.3 & 10 & 41.7 \\
\hline Clindamycin & 13 & 54.2 & 11 & 45.8 \\
\hline Erythromycin & 11 & 45.8 & 13 & 54.2 \\
\hline Penicillin & 8 & 33.3 & 16 & 66.7 \\
\hline
\end{tabular}


Table.6 Antibiotic sensitivity pattern of other Gram negative bacilli

\begin{tabular}{|c|c|c|c|c|}
\hline \multirow{2}{*}{ Antibiotic } & \multicolumn{2}{|c|}{ Sensitive } & \multicolumn{2}{|c|}{ Resistant } \\
\hline & Number & percentage & Number & Percentage \\
\hline Imepenem & 18 & 90 & 2 & 20 \\
\hline Amikacin & 18 & 90 & 2 & 20 \\
\hline Ciprofloxacin & 18 & 90 & 2 & 20 \\
\hline Gentamicin & 17 & 85 & 3 & 15 \\
\hline Tobramycin & 17 & 85 & 3 & 15 \\
\hline Meropenem & 17 & 85 & 3 & 15 \\
\hline Ofloxacin & 17 & 85 & 3 & 15 \\
\hline $\begin{array}{l}\text { Piperacillin } \\
\text { tazobactum }\end{array}$ & 16 & 80 & 4 & 20 \\
\hline Cefipime & 15 & 75 & 5 & 25 \\
\hline Ceftazidime & 14 & 70 & 6 & 30 \\
\hline Amoxyclav & 11 & 55 & 9 & 45 \\
\hline Ampicillin & 7 & 35 & 13 & 65 \\
\hline
\end{tabular}

Hence, diagnosis of the causative organism is necessary for proper management of CSOM cases (Prakash M et al., 2013).Topical and oral antimicrobials are prescribed to patients based on culture results when available, but the clinical benefit of antimicrobial therapy is not always clear. Surgery may prevent local, regional, or systemic complications, but some patients may continue to have ear discharge postoperatively (Neeff M et al., 2016).

CSOM can be characterized by co-infections with polymicrobial growth. In our study, monomicrobial growth was seen in $89.4 \%$ of cases which is similar to the previous study by Prakash M et al., and Agarwal et al., Mixed growth was seen in 5.8\% and no growth in $4.8 \%$ of cases.

The predominant organism isolated in our study is Pseudomonas (30.5\%) followed by $S$. aureus which is in accordance with other studies (Kaur et al., 2018, Saranya et al., 2015, Al-Hilli Z B et al., 2015, Arif D et al., 2014). But many other studies have shown $S$. aureus as the predominant organism (Vaidya K et al., 2015 \& Bizimana A et al., 2017).
Among fungi, the common organism isolated was Aspergillus species (18.1\%), which is in accordance with the study by Agarwal $\mathrm{R}$ et al., Next common fungi isolated was Candida species $(9.5 \%)$.

The injudicious and indiscriminate use of antibiotics has changed the microbiological flora. The knowledge of the microbiological spectrum is important to deliver efficacious treatment of this disease and also to prevent emergence of resistant strains (Chavan A et al., 2014).The important fact to be kept in mind is that the antibiotic susceptibility pattern of these CSOM causing organisms keeps changing. Hence, routine antibiotic susceptibility testing before treatment is recommended (Prakash, et al., 2013).

In the present study, Gram negative bacilli showed increased sensitivity to imepenem, ciprofloxacin, amikacin, meropenem, gentamicin, ofloxacin and high resistance to amoxyclav and cephalosporins. All the Staphylococcal isolates were sensitive to vancomycin, linezolid, teicoplanin and high resistance was noted to penicillin, erythromycin, clindamycin, amoxyclav. Our 
observations are similar with many other studies (Kumar et al., 2013, 2015).

CSOM is a global problem and affects mainly children due to their horizontal, wider and short Eustachian tube but can persist during adulthood following poor management of acute otitis media. It is a massive health problem in developing countries like India. Situation is more critical in rural areas because of lack of hygiene and knowledge. The present study gives knowledge about local pathogens that can assist in selection of most appropriate treatment which in turn improves the management of CSOM patients. Continuous and periodic evaluation of microbial pattern and antibiotic sensitivity of CSOM also helps to decrease the potential risks of complications.

\section{References}

Agrawal A, Kumar D, Goyal A, Goyal S, Singh N, Khandelwal G. 2013. Microbiological profile and their antimicrobial sensitivity pattern in patients of otitis media with ear discharge. Indian J Otol. 19:5-8

Agarwal R, Khatri P K, Parihar R S, Shah H. 2017. Microbial Assessment of Chronic Suppurative Otitis Media in a Tertiary Care Center of Rajasthan. International Journal of Health Sciences and Research. 7(2):120-6

Al-Hilli Z B. 2015. Study of Bacterial Isolates and their Susceptibility Pattern in Chronic Suppurative Otitis Media. IOSR Journal of Pharmacy and Biological Science. 10(6):1-5

Arif D, Mukhia R K, Goud S K, Nissar J, Shah R P, Singh S et al., 2014. Bacteriological Profile of Ear Infections and Its Antibiotic Susceptibility Pattern in a Tertiary Care Hospital Navi Mumbai. IOSR Journal of Dental and Medical
Sciences. 13(5):58-62

Arvind N, Chand P, Vishrutha K V. 2014. Microbiological Profile of Chronic Suppurative Otitis Media. International Journal of Biomedical Research. 5(03):204-6

Bizimana A, Hariharan M, Shrinivasan V, Deka A C. 2017. Microbiological Profile of Ear Infections In A Tertiary Care Hospital of Assam. European Jounal of Pharmaceutical And Medical Research. 4(4):363-5

Chavan A, Nagarkar R, Chavan G N, Deshmukh P T. 2014. A study of microbiological spectrum with its antibiotic susceptibility in patients of chronic suppurative otitis media at RIMS, Adilabad (AP). International Journal of Healthcare and Biomedical Research. 3(1):152-7

Collee J G, Duguid J P, Fraser A G, Marmion B P, Simmons A. 1996. Laboratory strategy in the diagnosis of infective syndromes. Mackie and McCartney practical medical microbiology, 14th ed. Churchill Livingstone, Singapore. pp. 53-94.

Harshika Y K, Sangeetha S, Prakash R. 2015. Microbiological Profile of Chronic Suppurative Otitis Media and their Antibiotic Sensitivity Pattern in a Tertiary Care Hospital. Int.J.Curr.Microbiol.App.Sci. 4(12):735-43

Kaur P, Sood A S, Sharma S, Awal G. 2018. Microbiological Profile and antimicrobial susceptibility pattern of chronic suppurative otitis media in a tertiary care center. Pathology Update:Tropical Journal of Pathology and Microbiology. 4(1):3-13

Kumar R, Agarwal R K, Gupta S. 2015. A Microbiological Study of Chronic Suppurative Otitis Media. International Journal of Recent Scientific Research. 6(7):5487-90 
Kumar R, Srivastava P, Sharma M, Rishi S, Nirwan PS, Hemwani K et al., 2013. Isolation and Antimicrobial sensitivity profile of bacterial agents in Chronic Suppurative Otitis Media patients at NIMS hospital, Jaipur. International Journal of Pharmacy and Biological Sciences. 3(4):265-9

Mehta M, Saha P, Kunkulol R, Simar H, Mehta N. 2017. Microbiological Profile and Antibiotic Sensitivity Pattern of Active Mucosal Chronic Otitis Media and Active Squamous Chronic Otitis Media (with Cholesteatoma) in a Tertiary Care Hospital of Hisar, (Haryana) India. Ann Clin Otolaryngol. 2(3):1019.

Neeff M, Biswas K, Hoggard M, Taylor MW, Douglas R. 2016. Molecular Microbiological Profile of Chronic Suppurative Otitis Media. Journal of Clinical Microbiology. 54(10):2538-46

Prakash M, Lakshmi K, Anuradha S, Swathi G N. 2013. Bacteriological profile and their antibiotic susceptibility pattern of cases of Chronic Suppurative Otitis Media. Asian Journal of Pharmaceutical and Clinical Research. 6(3):210-2

Rajesh S, Sukumar N. 2017. Microbiological profile of Chronic Suppurative Otitis
Media (CSOM) in a tertiary care hospital. International Journal of Bioassays pp:5355-9.

Saranya S K, Vazhavandal G, Ganesh B V, Ismail M, Uma A, Subramaniam T P. 2015. Bacteriological and Mycological Profile of Chronic Suppurative Otitis Media In A Tertiary Teaching Hospital, Trichy, Tamilnadu. Internal Journal of Pharmaceutical Science Invention. 4(1):13-9

Shreshta B L, Amatya R C M, Shreshta I, Ghosh I. 2011. Microbiological profile of Chronic suppurative otitis media. Nepalese Journal of ENT Head \& Neck Surgery. 2(2):6-7.

Toleti S. 2016. Bacterial profile and antibiotic susceptibility pattern of chronic suppurative otitis media in a tertiary teaching hospital, Chinakakani, Andhra Pradesh. International Journal of Information Research and Review. 3(10):2866-8.

Vaidya K, Madhup S K, Shreshta B L, Gautam A, Tuladhar N R. 2015. Bacteriological and Mycological profile of Chronic Suppurative Otitis Media among patients visiting Dhulikhel Hospital. ACCLM. 1(1):3741

\section{How to cite this article:}

Shwetha, D. C., G. C. Ravi, D. Venkatesha, S. Megha and Greeshma, P. G. 2021. Microbiological Profile of Chronic Suppurative Otits Media and their Antibiogram in A Rural Tertiary Care Hospital. Int.J.Curr.Microbiol.App.Sci. 10(08): 448-455. doi: https://doi.org/10.20546/ijcmas.2021.1008.055 